The Relationship between Emotional Intelligence and Psychological Wellbeing of Undergraduates of the Faculty of Management Studies and Commerce, University of Sri Jayewardenepura

\author{
Makuloluwa, IU and Arachchige, BJH
}

\begin{abstract}
Area of the Study

This study seeks to explore the relationship between emotional intelligence (EI) and psychological wellbeing of management undergraduates of the Faculty of Management Studies and Commerce, University of Sri Jayewardenepura as a contemporary topic among the scholars.
\end{abstract}

\title{
Problem of the Study
}

There is an empirical and knowledge gap in the Sri Lankan context on the relationship between emotional intelligence and psychological well being of undergraduates. This study is aimed to reveal the relationship between emotional intelligence and psychological well being of management undergraduates in the University of Sri Jayewardenepura.

\section{Method of the Study}

The data were collected from 120 undergraduates (60 males and 60 females) and stratified sampling method was used to categorize the population, department wise and then the simple random sampling procedure was used for selecting the sample from the departments to collect data. Structured questionnaire which consisted Singh's (2006) 22 items scenario based EI quotient and Ryff's (1989) 42 items psychological wellbeing questionnaire were administered. Pearson Product Moment of Coefficient of Correlation and One Way Anova was used in order to find out the relationship of EI with psychological wellbeing of undergraduates.

\section{Findings of the Study}

This study found out that emotional intelligence is positively correlated with psychological well being. Moreover, emotional intelligence is positively correlated with each dimension of psychological wellbeing namely self acceptance, purpose in life, positive relations, personal growth, environmental mastery and autonomy.

\section{Conclusion of the Study}

It is concluded that the greater emotional intelligence is positively correlated with high level of psychological wellbeing of management undergraduates. Further, this research supported the view that emotionally intelligent undergraduates enjoy greatest happiness in their life.

Keywords: Emotional Intelligence, Psychological Wellbeing, Self Acceptance, Purpose in Life, Personal Growth

\section{Introduction}

In everyday life, emotions play a very important role in deciding the behavior of human beings and how they react in various situations. Simply emotional intelligence means the amalgamation of emotions and intelligence. Edward Thorndike was the person who initiated 
the study of emotional intelligence as a dimension of social intelligence (Click 2002). Salovey and Mayer were given credit for introducing the term "emotional intelligence" in early 1990s (Click 2002) and finally, Daniel Goleman described emotional intelligence in the context of workplace (Click 2002).

Psychological well being is a complex and multidimensional construct. As mentioned by Carmeli et al. (2009) simply, psychological wellbeing stands for "a generalized feeling of happiness" (Schmutte \& Ryff 1997 p. 551). Further Ryff and Keyes introduced the multidimensional framework which consists of six different components of positive psychological functioning. These dimensions include, a span of wellness that includes positive evaluations of oneself and one's past life (Self-Acceptance), a sense of sustained growth and development as a person (Personal Growth), the belief that one's life is purposeful and meaningful (Purpose in Life), the holding of quality relations with others (Positive Relations with Others), the capacity to manage effectively one's life and immediate environment (Environmental Mastery), and a sense of self-determination (Autonomy) (Ryff \& Keyes 1995).

There has been substantial evidence proving that being emotionally intelligent can help individuals excel through life transitions starting from school to university and later into the working world. At the university level, emotional intelligence is seen as a valuable skill that helps students to manage and cope with the demanding nature of the university. Thus, it is important to study that the extent to which undergraduates scored higher in EI experienced better psychological wellbeing.

\section{Problem Background and Problem of the Study}

Theory suggests that emotionally intelligent individuals are likely to experience a higher level of psychological wellbeing and a lower level of emotional deficit than individuals who possess a low level of EI (Carmeli 2009). Therefore, this research also attempts to provide more comprehensive evidence by investigating the relationship between EI and psychological wellbeing as a multidimensional construct encompassing self acceptance, purpose in life, positive relations, personal growth, environmental mastery and autonomy among the final year management undergraduates of the University of Sri Jayewardenepura.

\section{Research Framework}

The conceptual framework of the study is given in Figure 01. 
Figure 1: Conceptual Framework

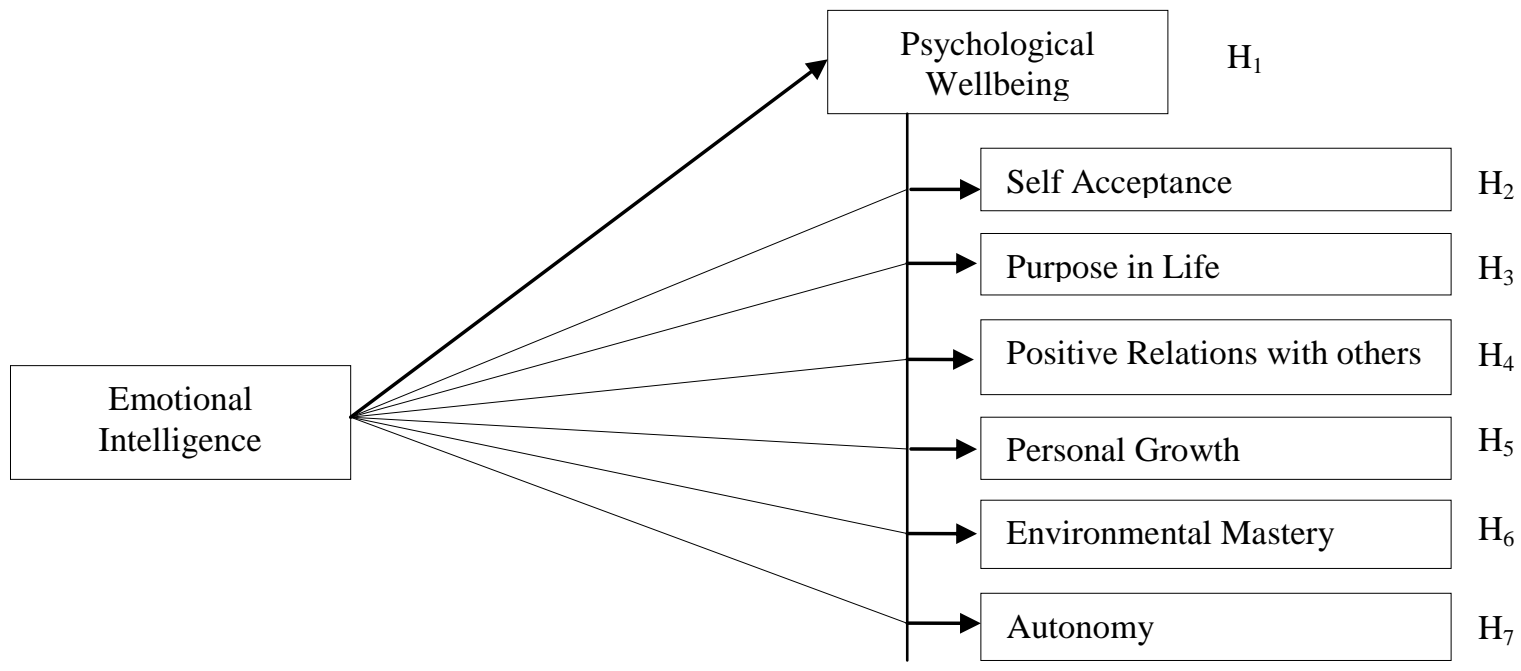

The conceptual framework shown in figure 01 depicts seven hypotheses of these two phenomena.

Previous researchers found that EI significantly correlates with psychological well being (Ugoani and Ewuzie 2013). According to Carmeli et al. (2009), individuals reporting higher EI reported higher levels of life satisfaction, self-acceptance, and self-esteem than individuals who are relatively low in emotional intelligence. Berges and Landa (2014) found that nurses who tried to increase or maintain their positive emotional intensity and to reduce or eliminate negative emotions reported a higher life satisfaction and wellbeing. As Landa et al. (2010) stated EI components were positively related to all dimensions of psychological wellbeing. The first hypothesis was developed as:

$\mathrm{H}_{1}$ : There is a positive relationship between emotional intelligence and psychological wellbeing.

With reference to Shahzad et al. (n.d.) individuals with higher levels of self regard tend to see themselves as effective and adequate and report higher self worth and value. Landa et al. (2010) found that individuals with a high differentiation of their emotional experience who are able to maintain or enhance the intensity of positive emotions and reduce or eliminate negative emotions report high self acceptance. The second hypothesis was formed as:

$\mathrm{H}_{2}$ : There is a positive relationship between emotional intelligence and self acceptance.

The research done by Shahzad et al. (n.d.) pointed out that trait EI is positively correlates with a purpose in life. It means that those who have higher trait EI would develop better goals and targets in their lives, have a sense of direction and give positive meaning to their present and past lives. According to Landa et al. (2010) individuals with a high degree of emotional intelligence reported high life purpose. The third hypothesis was formulated as:

$\mathrm{H}_{3}$ : There is a positive relationship between emotional intelligence and purpose in life.

Those who are able to manage their own emotions are in a position to influence other people's expectations for social interaction (Shahzad et al n.d.). Carmeli et al. (2009) and 
Lopes et al. (2003) reported that college students who are high in EI exhibit a high level of quality social relationships. Landa et al. (2010) found that EI positively correlated with positive relations with others. The fourth hypothesis was developed as:

$\mathrm{H}_{4}$ : There is a positive relationship between emotional intelligence and positive relationship with others.

As Shahzad et al. (n.d.) mentioned, those who have higher levels of trait EI, would have higher levels of personal growth also. As mentioned by Landa et al. (2010) individuals with a high differentiation of their emotional experience (clarity) and who are able to maintain or enhance the intensity of positive emotions and reduce or eliminate negative emotions report high personal growth. Thus the fifth hypothesis was developed as:

$\mathrm{H}_{5}$ : Emotional intelligence will be positively correlated with personal growth.

There are research findings in individuals with higher than average EI was more successful in meeting environmental demands and pressures than others (Shahzad et al n.d.). As Landa et al. (2010) mentioned, individuals who are high in EI predict a greater ability to create positive environments. The sixth hypothesis was formulated as:

$\mathrm{H}_{6}$ : Emotional intelligence will be positively correlated with environmental mastery.

Shahzad et al. (n.d.) found individuals who perceive themselves as self-determining and independent have the ability to face social stress and regulate their behaviour with internal frame of reference and also evaluate their personal standards positively. According to Landa et al. (2010) EI showed a positive relationship with the autonomy. The seventh hypothesis was developed as:

$\mathrm{H}_{7}$ : Emotional intelligence will be positively correlated with autonomy.

\section{Method}

\section{Study Design}

This study was a correlational study in which the relationship between variables is examined and was undertaken in a natural/non contrived environment. It was conducted in the premises of University of Sri Jayewardenepura. This research was a cross-sectional study, which gathered data for one - time using a questionnaire. The unit of analysis used in this study was individual.

The population selected to carry out this study was the final year Bachelor degree students of the Faculty of Management Studies and Commerce of the University of Sri Jayewardenepura. The students were enrolled in a variety of programmes, namely Accounting, Finance, Economics, Human Resource Management, Business Administration, Information Technology, Entrepreneurship, Operational and Technology Management, Estate Management and Valuation, Public Administration and Commerce. Data were gathered through a survey and the sample size for this study was 120 participants (60 girls and 60 boys) from the population of the final year undergraduates (around 1200 undergraduates). In this study, the sampling method used was the stratified random sampling technique and simple random sampling technique. This study utilized stratified sampling to categorize the 
population, department-wise and then used the simple random sampling procedure to select samples from the departments.

\section{Measures}

Although the literature describes various instruments for measuring EI, the Emotional Quotient Test developed by Professor NK Chanda and Dr Dalip Singh was used as a measurement instrument of emotional intelligence in this study. It consisted of 22 items which was developed based on small scenario to measure EI.

Ryff's psychological wellbeing scale (PWS) was used to measure six dimensions of psychological wellbeing. The questionnaire consisted of 42 items with six Likert scale and each element was measured by using seven questions which indicated both negative and positive aspects.

\section{Validity and Reliability}

A pilot test was carried out using 30 management undergraduate's responses (15 boys and 15 girls) from the University of Sri Jayewardenepura. As shown in Table 1 the results of the Cronbach's Alfa test are reasonable enough to ensure the reliability of this study. The results of Cronbach's alpha test suggest that the internal reliability of each instrument (Kottawatta 2014).

Table 1: Cronbach's Alpha Coefficients

\begin{tabular}{|l|c|}
\hline Instrument & Cronbach's Alpha \\
\hline Psychological Wellbeing & .854 \\
\hline
\end{tabular}

The content validity of the instruments was ensured by the conceptualization of the variables on literature (Kottawatta 2014) and the content validity of the variables of the study was ensured by the fact that the correlation support the hypotheses formulated linking the relationship between the independent variables and the dependent variable (Kottawatta 2014).

\section{Techniques of Data Analysis}

Data collected from the survey were analyzed using the Computer Based Statistical Data Analysis Package, SPSS (version 16.0) for validity, reliability, and relationship testing. The data analyzed included univariate, and bivariate analyses.

\section{Results and Discussion}

Univaraite analysis was used to investigate the responses for emotional intelligence and psychological wellbeing with its six dimensions. The results of the univariate analysis are given in Table 2. 
Table 2: Descriptive Statistics of EI and Psychological Wellbeing with its Six Dimensions

\begin{tabular}{|c|c|c|c|c|c|c|c|c|}
\hline & 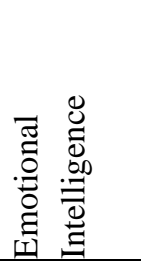 & 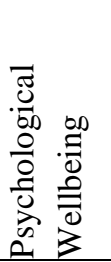 & 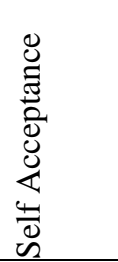 & 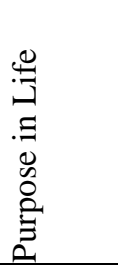 & 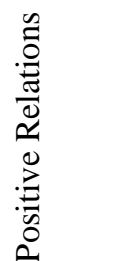 & 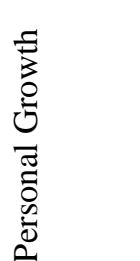 & 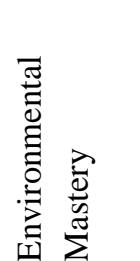 & 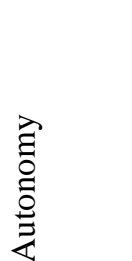 \\
\hline Mean & 352.41 & 4.2563 & 4.4238 & 4.1202 & 4.3902 & 4.4526 & 4.0940 & 4.1453 \\
\hline Median & 355.00 & 4.3333 & 4.4286 & 4.1429 & 4.4286 & 4.4286 & 4.1429 & 4.1429 \\
\hline Mode & 360 & $3.64^{\mathrm{a}}$ & 4.57 & $3.71^{\mathrm{a}}$ & 5.00 & 4.43 & 4.29 & 4.43 \\
\hline Std. Deviation & 24.276 & .51795 & .76673 & .67567 & .72072 & .71436 & .47380 & .59495 \\
\hline Variance & 589.340 & .268 & .588 & .457 & .519 & .510 & .224 & .354 \\
\hline Skewness & -.861 & .099 & -.042 & .022 & -.157 & .269 & -.112 & .314 \\
\hline $\begin{array}{l}\text { Std. Error of } \\
\text { Skewness }\end{array}$ & .225 & .226 & .221 & .221 & .222 & .222 & .221 & .224 \\
\hline Kurtosis & .916 & -.483 & -.412 & -.148 & -.607 & -.483 & -.005 & .593 \\
\hline $\begin{array}{l}\text { Std. Error of } \\
\text { Kurtosis }\end{array}$ & 446 & 447 & 438 & 438 & .440 & 440 & .438 & 444 \\
\hline Minimum & 275 & 3.19 & 2.57 & 2.00 & 2.86 & 3.14 & 2.71 & 2.71 \\
\hline Maximum & 405 & 5.55 & 6.00 & 5.86 & 6.00 & 6.00 & 5.29 & 6.00 \\
\hline
\end{tabular}

Table 2 reports the results of the descriptive data analysis of the research variables. Mean value of emotional intelligence is 352.41 which is in the range of high EI level (379-308). Therefore, it can be said that undergraduates possess a high level of emotional intelligence. Psychological wellbeing scale is six in Likert scales. Hence the average mean value is 3.5 $(1+2+3+4+5+6 / 6)$. If the mean value is greater than 3.5 then the psychological wellbeing of the respondents is high. As per table 2, mean value of psychological wellbeing is 4.2563. Therefore, it is indicated that undergraduates have high levels of psychological wellbeing. The dimensions of psychological wellbeing namely self acceptance, purpose in life, positive relations, personal growth, environmental mastery and autonomy have mean values of $4.4238,4.1202,4.3902,4.4526,4.0940$, and 4.1453 respectively. Thus undergraduates perceive a high level of self acceptance, purpose in life, positive relations, personal growth, environmental mastery and autonomy since all mean values are greater than the average mean value.

Table 3: Relationship of emotional intelligence with psychological wellbeing, self acceptance, purpose in life, positive relations, personal growth, environmental mastery and autonomy

\begin{tabular}{|l|c|c|}
\hline Variables & Pearson (r) & Sig. (i-tailed) \\
\hline Psychological Wellbeing & $.289^{* *}$ & .002 \\
\hline Self Acceptance & $.231^{*}$ & .013 \\
\hline Purpose in Life & $.277^{* *}$ & .003 \\
\hline Positive Relations & $.245^{* *}$ & .008 \\
\hline Personal Growth & $.216^{*}$ & .020 \\
\hline Environmental Mastery & $.272^{* *}$ & .003 \\
\hline Autonomy & $.214^{*}$ & .022 \\
\hline \multicolumn{2}{|c|}{$* *$ Correlation is significant at the 0.01 level (2-tailed). }
\end{tabular}


According to the Pearson's correlation coefficients (Table 03) of .289 it can be said that there is a positive relationship between emotional intelligence and psychological wellbeing. Moreover, components of psychological well being namely self acceptance, purpose in life, positive relations, personal growth, environmental mastery and autonomy represents the positive values of Pearson's correlation coefficients. Therefore, it indicated that EI is positively correlated with psychological wellbeing and its components.

Table 4: One Way Anova Analysis

\begin{tabular}{|c|c|c|c|c|c|}
\hline & Sum of Squares & Df & Mean Square & $\mathrm{F}$ & Sig. \\
\hline $\begin{array}{l}\text { Psychological Wellbeing } \\
\text { Between Groups } \\
\text { Within Groups } \\
\text { Total }\end{array}$ & $\begin{array}{r}2.967 \\
26.220 \\
29.188\end{array}$ & $\begin{array}{r}2 \\
110 \\
112\end{array}$ & $\begin{array}{r}1.484 \\
.238\end{array}$ & 6.224 & .003 \\
\hline $\begin{array}{l}\text { Self Acceptance } \\
\text { Between Groups } \\
\text { Within Groups } \\
\text { Total }\end{array}$ & $\begin{array}{r}5.229 \\
62.265 \\
67.494 \\
\end{array}$ & $\begin{array}{r}2 \\
113 \\
115 \\
\end{array}$ & $\begin{array}{r}2.614 \\
.551\end{array}$ & 4.745 & .011 \\
\hline $\begin{array}{l}\text { Purpose in Life } \\
\text { Between Groups } \\
\text { Within Groups } \\
\text { Total }\end{array}$ & $\begin{array}{r}2.102 \\
50.257 \\
52.359\end{array}$ & $\begin{array}{r}2 \\
113 \\
115\end{array}$ & $\begin{array}{r}1.051 \\
.445\end{array}$ & 2.363 & .099 \\
\hline $\begin{array}{l}\text { Positive Relations } \\
\text { Between Groups } \\
\text { Within Groups } \\
\text { Total }\end{array}$ & $\begin{array}{r}3.973 \\
54.683 \\
58.656\end{array}$ & $\begin{array}{r}2 \\
113 \\
115\end{array}$ & $\begin{array}{r}1.986 \\
.484\end{array}$ & 4.105 & .019 \\
\hline $\begin{array}{l}\text { Personal Growth } \\
\text { Between Groups } \\
\text { Within Groups } \\
\text { Total }\end{array}$ & $\begin{array}{r}4.800 \\
51.975 \\
56.775\end{array}$ & $\begin{array}{r}2 \\
112 \\
114\end{array}$ & $\begin{array}{r}2.400 \\
.464\end{array}$ & 5.171 & .007 \\
\hline $\begin{array}{l}\text { Environmental Mastery } \\
\text { Between Groups } \\
\text { Within Groups } \\
\text { Total }\end{array}$ & $\begin{array}{r}2.508 \\
22.681 \\
25.190\end{array}$ & $\begin{array}{r}2 \\
113 \\
115\end{array}$ & $\begin{array}{r}1.254 \\
.201\end{array}$ & 6.248 & .003 \\
\hline $\begin{array}{l}\text { Autonomy } \\
\text { Between Groups } \\
\text { Within Groups } \\
\text { Total }\end{array}$ & $\begin{array}{r}2.962 \\
36.914 \\
39.877\end{array}$ & $\begin{array}{r}2 \\
111 \\
113\end{array}$ & $\begin{array}{r}1.481 \\
.333\end{array}$ & 4.454 & .014 \\
\hline
\end{tabular}

According to table 4, all other variable's $\mathrm{P}$ value is less than 0.05 apart from the value of purpose in life. Thus, it is indicated that the mean value of each variable differs according to the categorical level of EI (extremely high EI, high EI and moderate EI). A further post hoc test was carried out and the results of post hoc test showed that high values of EI associated with higher mean values of psychological wellbeing. However, the $\mathrm{P}$ value of purpose in life is 0.99 and it is greater than the 0.05 . Hence the purpose of life has not shown significant difference, according to the level of EI. Further the mean value of purpose in life is same in each categorical level of emotional intelligence. 


\section{Conclusion}

According to the findings of this study it is found that EI is positively correlated with psychological wellbeing. The research findings of Ugoani and Ewuzie (2013), Carmeli et al. (2009), Berges and Landa (2014) and Landa et al. (2010) supported to confirm the finding of this study. The finding of positive relationship between EI and psychological wellbeing is established by the study conducted by Shahzad et al. (n.d.) and Landa et al. (2010). The research findings of Shahzad et al. (n.d.) and Landa et al. (201) were redefined by this study as there is a positive relationship between EI and purpose in life. Positive relationship between EI and positive relations with others, as a research finding of this study was discussed in the previous studies carried out by Shahzad et al. (n.d.), Carmeli et al. (2009), Lopes et al. (2003) and Landa et al. (2010). The fifth hypothesis of the study; EI will be positively correlated with personal growth was validated through the study done by Shahzad et al. (n.d.) and Landa et al. (2010). This study found out that there is a positive correlation between EI and environmental mastery which was corroborated by Shahzad et al. (n.d.) and Landa et al. (2010). At the same time, Shahzad et al. (n.d.) and Landa et al. (2010) found that EI positively correlates with autonomy, which is confirmed by the finding of this study itself.

\section{Recommendations}

Thus, in order to enhance the EI of management undergraduate training programs, counseling programs could be arranged and the degree programs also could be improved by introducing new subjects which might assist to improve EI of management undergraduates. In addition, as a suggestion for further research it would be important to conduct studies that examine the impact of EI on the psychological wellbeing of undergraduates. This research used only a group of undergraduates, thus it is recommendable to carry out the research again using different samples from different populations. It is suggested that it is important to conduct this kind of research in qualitative methods as well.

\section{References}

i. $\quad$ Berges, BM \& Landa, JM 2014, 'Emotional Intelligence and Affective Intensity as Life Satisfaction and Psychological Well- Being Predictors on Nursing Professionals', Journal of Professional Nursing, Vol. 30, No. 1, pp. 80-88.

ii. Carmeli, A, Yitzhak-Halevy, M \& Weisberg, J 2009, 'The relationship between emotional intelligence \& psychological wellbeing', Journal of Managerial Psychology, Vol. 24, No. 1, pp. 66-78.

iii. Click, HS 2002, An Exploration of Emotional Intelligence Scores among Students in Educational Administration Endorsement Programs, Electronic thesis \& Dissertations, East Tennessee State University.

iv. Kottawatta, H 2014, Research guide book, Department of Human Resource Management, Colombo.

v. Landa, JMA, Matos, MP \& Zafra, EL 2010, 'Emotional Intelligence and Personality Traits as Predictor of Psychological Wellbeing in Spanish Undergraduates', Social Behaviour and Personality, vol. 38, no. 6, pp. 783-794. 
vi. Lopes PN, Salovey P \& Straus R 2003, 'Emotional Intelligence and personality, and the perceived quality of social relationship', Personality and individual difference, No. 35, pp.641-658.

vii. Montes-Berges, B \& Augusto-Landa, JM 2014, 'Emotional intelligence and affective intensity as life satisfaction and psychological wellbeing predictors on nursing professionals', Journal of Professional Nursing, vol. 30, no. 1, pp. 80-88.

viii. Ryff, CD \& Keyes, CLM 1995, 'The structure of psychological wellbeing revisited', Journal of Personality and Social Psychology, Vol. 69, No. 4, pp. 719-727.

ix. Ryff, CD 1989, 'Happiness is everything, or is it? Explorations on the meaning of psychological wellbeing', Journal of Personality and Social Psychology, Vol. 57, No. 6, pp. 1069-1081.

x. Schmutte, PS \& Ryff, CD 1997, 'Personality and well-being: Reexamining methods and meanings', Journal of Personality and Social Psychology, Vol. 73, No. 3, pp. 549-559. http://dx.doi.org/10.1037/0022-3514.73.3.549.

xi. Shahzad, S, Sadaf, N \& Begum, N n.d., 'Trait Emotional Intelligence and Psychological Wellbeing in Drug Addicts: A Correlational Study', International Journal of Prevention and Treatment of Substance Use Disorders, pp. 28-37

xii. Singh, D 2006, Emotional Intelligence at Work, A professional Guide, Sage Publications, New Delhi.

xiii. Ugoani, JNN \& Ewuzie, MA 2013, 'Imperatives of Emotional Intelligence on Psychological Wellbeing among Adolescents', American Journal of Applied Psychology, vol. 1, no. 3, pp. 44-48.

Makuloluwa, IU

Department of Human Resource Management, University of Sri Jayewardenepura ish.upamali@yahoo.com

\section{Arachchige, BJH}

Senior Lecturer, Department of Human Resource Management, University of Sri Jayewardenepura bhadra@sjp.ac.lk, bhadra-arachchige@yahoo.com 